\title{
Review Article \\ Human Serum Eye Drops in Eye Alterations: An Insight and a Critical Analysis
}

\author{
Maria Rosaria De Pascale, ${ }^{1}$ Michele Lanza, ${ }^{2}$ Linda Sommese, ${ }^{1}$ and Claudio Napoli ${ }^{1}$ \\ ${ }^{1}$ U.O.C. Immunohematology, Transfusion Medicine and Transplant Immunology, Regional Reference Laboratory of \\ Transplant Immunology, Azienda Ospedaliera Universitaria (AOU), Second University of Naples, 80100 Naples, Italy \\ ${ }^{2}$ Multidisciplinary Department of Medical, Surgical and Dental Sciences, Second University of Naples, 80100 Naples, Italy \\ Correspondence should be addressed to Michele Lanza; mic.lanza@gmail.com
}

Received 17 May 2015; Accepted 7 July 2015

Academic Editor: Flavio Mantelli

Copyright (c) 2015 Maria Rosaria De Pascale et al. This is an open access article distributed under the Creative Commons Attribution License, which permits unrestricted use, distribution, and reproduction in any medium, provided the original work is properly cited.

\begin{abstract}
Human serum contains a physiological plethora of bioactive elements naturally released by activated platelets which might have a significant effect on the regeneration of corneal layers by stimulating the cell growth. This mechanism supported the use of human serum eye drops in some ocular diseases associated with dystrophic changes and alterations of the tear film, such as persistent corneal epithelial defects and dry eye syndrome. We focused our effort on potential benefits and limitations of the use of human serum eye drops when conventional therapies failed. We reviewed the recent literature by reporting published studies from 2010 to 2014. Despite the limited evaluated study populations, most of the clinical studies have confirmed that serum eye drop therapy is effective in corneal healing by reducing ocular symptom, particularly during the short-term follow-up. In addition, three recent published studies have shown the efficacy of the serum eye drop therapy in comparison to traditional ones in intractable patients. Besides, reported ongoing clinical studies confirmed the open debate regarding the use of biologic tools for cornea regeneration. Results from these studies might open novel challenges and perspectives in the therapy of such refractory patients.
\end{abstract}

\section{Introduction}

Cornea is mostly composed of collagen and water and is enveloped by epithelium and endothelium [1]. These layers cooperate to ensure tissue homeostasis by providing adequate corneal transparency and reliability [1]. After injury, corneal epithelial cells regenerate and restore the physiologic tissue architecture. In addition, a concomitant nerve regrowth and a controlled neovascularization of the damaged surface may occur $[2,3]$. Cellular loss needs replacement by cell growth and migration [3]. The mechanism driving the epithelialization involves a multiplicity of cells stimulated by serum growth factors (GFs) (Table 1) [4-6], mostly contained in platelet- $\alpha$ granules and issued by the same GFs into the blood during stress and tissue repair [4-10]. The great quantity and accessibility of GFs and other signaling proteins in platelets with a consequent inhibition of cell apoptosis and improvement of cell proliferation, differentiation, and migration suggested the extensive use of platelet derivatives for clinical and surgical aims in regenerative medicine (Table 1 and Figure 1) [7, 11]. Indeed, GFs, binding to tyrosine kinase or G protein-coupled receptor families, drive both the inflammatory process and the stroma remodeling through autocrine, juxtacrine, or, most commonly, paracrine means. Thus, the transcription of critical proteins for cell cycle returning to prewounding levels after the tissue healing occurs (Table 1) $[12,13]$.

Particularly, serum GFs such as epidermal growth factor (EGF), hepatocyte growth factor (HGF), and keratinocyte growth factor (KGF) stimulate corneal wound closure accelerating the healing time. Moreover, transforming growth factor- $\beta 1 / \beta 2$ (TGF $\beta 1 / \beta 2$ ) induces myofibroblast from fibroblast differentiation coupled to corneal opacification (corneal haze) (Table 1) [14-16]. Moreover, cytokines derived from the trigeminal nerve like substance $P$, neuropeptide $y$, catecholamines, and acetylcholine are positively involved in corneal healing [17]. Besides, an aged decreased response to mitogens mediated by alterations in the expression and 


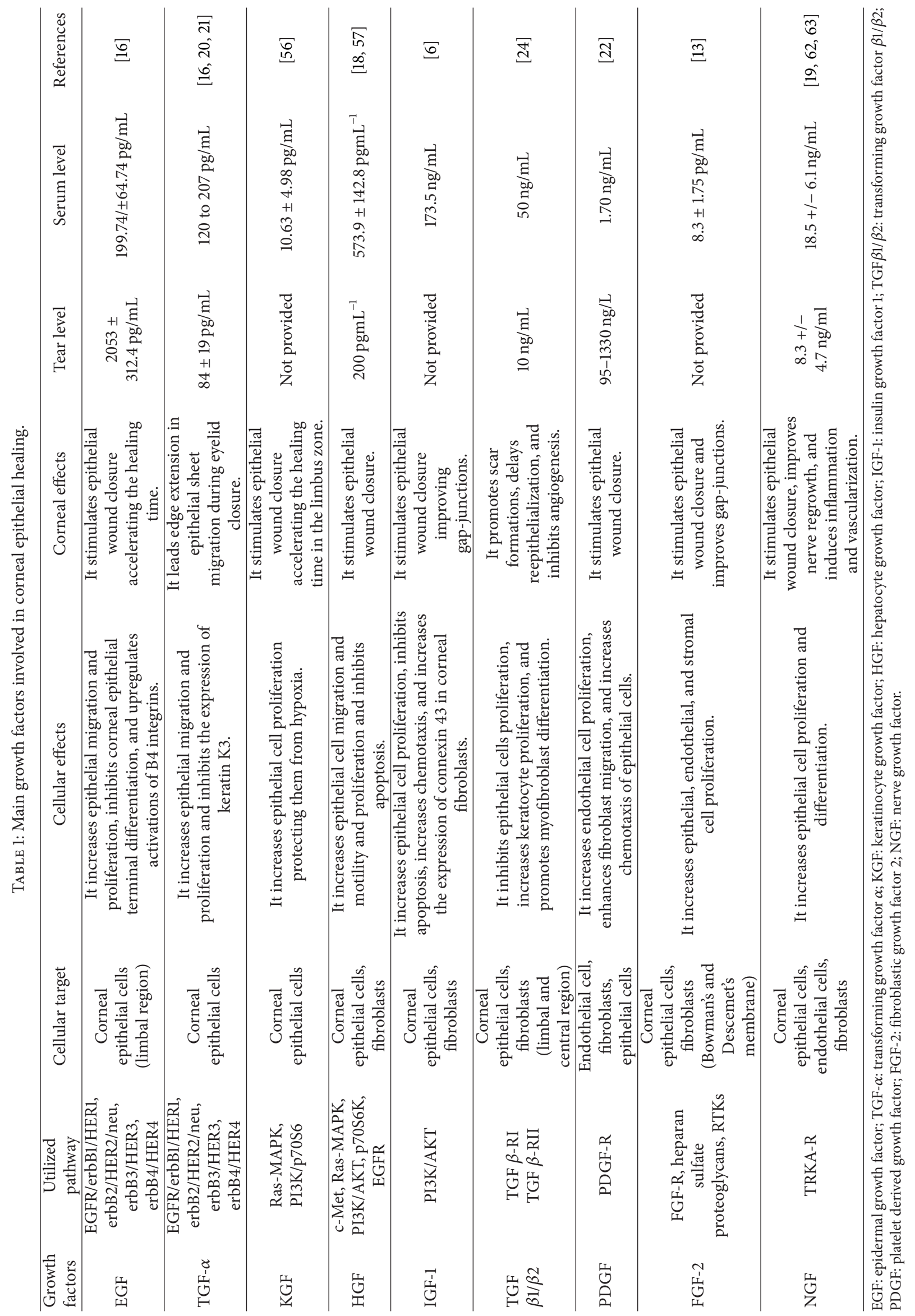






FIGURE 1: Mechanisms involved in damaged cornea and serum growth factor regeneration pathways. Several corneal injures can promote pathological conditions such as PED or DES. Action of drugs, autoimmune diseases, aging, chemical insults, and postsurgical lesions can wound the cornea directly or indirectly through the imbalance of the lachrymal gland. Microscopically, these pathogenic conditions result in a loss of epithelial cells and microvilli, epithelial squamous metaplasia, and inflammation of the corneal surface. The corneal healing process can benefit from the promoting action of serum GFs. Once they are released, through tyrosine kinase receptors, they propagate their signal from the plasma membrane to the nucleus. Through explicit pathways and signaling cascades, GFs activate the expression of target genes involved in apoptosis, proliferation, cell differentiation, and migration. This synergistic action establishes regenerative effects with closure of epithelial lesions, revascularization, and neurorepair.

activity of cyclin-dependent kinase inhibitors (p27KIP1, p16INK4A, and p21CIP1) appears to be involved in a lacking or a damaging of cellular repair processes [3].

Toward this context, the lachrymal film plays a critical role such as resource of GFs [18-24] since the lack of tear epitheliotropic support promotes corneal opacity onset with consequent visual impairment [25]. On the other hand, tear upregulation drives corneal epithelial hyperplasia, excessive deposition of extracellular matrix, and hypervascularization with cornea conjunctivalization [8]. Here, we report the different concentrations of each GF in the human serum with respect to tears. The levels of transforming growth factor $\alpha$ (TGF- $\alpha$ ), hepatocyte growth factor (HGF), TGF $\beta 1 / 2$, and nerve growth factor (NGF) resulted to be even more elevated in serum than in tears.
Failure of the corneal repair mechanisms leads to a chronic pathologic condition as persistent epithelial defects (PED) or dry eye syndrome (DES) [15]. PED result from several factors such as aging, chemical burns, systemic disorders, and drugs [26] (Figure 1). Nevertheless, DES, associated to tear deficit or tear inefficiency, is able to promote the corneal epithelial instability and inflammation [27, 28] supporting PED syndrome. DES is caused by lacrimal gland imbalance often connected to systemic inflammatory diseases [29-32], such as Sjogren's syndrome [33], rheumatoid arthritis [31], diabetes [34], systemic lupus erythematosus, acne rosacea, and Graves' disease [35]. In addition, hormonal modifications, drugs (e.g., systemic antihistamines, diuretics, and topical beta blockers for glaucoma therapies), and surgeries (e.g., photorefractive keratectomy and laser 
in situ keratomileusis) [36] as well as the repeated use of contact lenses could be involved in DES development [27]. On the basis of mechanistic criteria, International Dry Eye WorkShop has characterized two main subtypes of the disorder (aqueous deficiency and evaporative dry eye) both interested by tear film instability and symptoms of discomfort $[28,37]$. Ocular dryness or irritation might increase light sensitivity, foreign body sensation, red eyes, poor vision, and daily life limitations which are the most referred symptoms which have great impact on patient quality of life $[37,38]$. The best clinical marker for DES diagnosis and for the severity assessment is represented by the improved tear osmolarity [39]. In addition, tear production is currently evaluated by Schirmer's testing, fluorescein clearance, and fluorescein tear break-up time (TBUT). The ocular surface damage is estimated through dye staining (fluorescein and lissamine green) while the severity of subjective symptoms is assessed by subjective scored questionnaires (like OXFORD score and Ocular Surface Disease Index) $[37,38]$.

Up to now, there is no gold standard therapy for DES or PED [40-42]. Current therapeutic strategies require the accurate identification of etiologic mechanisms that cause the corneal injury by providing epitheliotropic factors and enhancing tear replacement $[26,43,44]$. When standard therapeutic options fail, the main treatment purpose is the increased patient comfort and corneal moisture through the instillation of artificial tears, corticosteroids, antibiotics, and use of bandage contact lenses [30, 45-47]. However, natural tears have a particular composition of water, salts, hydrocarbons, proteins, and lipids that cannot be restored by pharmacological alternatives [25]. Furthermore, artificial tear substitutes contain chemical preservatives associated with toxic and allergic reactions, especially for those patients with sensitive eyes [6]. Moreover, the repeated instillation of topical corticosteroids could be associated with long-term side effects including cataracts and increased intraocular pressure [48]. For these motivations, alternative therapies like silicone punctal plug insertion, botulinum neurotoxin type A, nutritional supplements (essential fatty acids, including omega-3, linoleic acid, and gamma-linoleic acid), and topical $0.05 \%$ solution of cyclosporine A have been proposed [4955]. However, changes in life style as an increased water intake and reduction of alcohol consumption, indoor humidifiers, and air filters or cleaners have been recommended [56].

A debated aspect of the treatment of corneal diseases is focused on the use of novel regenerative instruments for corneal regeneration [57-60]. The evidence regarding the key role of several GFs for the integrity of the ocular surface (Table 1) fits the use of single recombinant GFs in several human corneal degenerative disorders [57-61]. Nerve growth factor (NGF) alteration in corneal diseases has been largely evaluated; NGF pathway alteration has been tested in an animal model by demonstrating NGF to be involved in corneal healing and in sensory denervation [62]. Moreover, in studies evaluating human being, low tears level of NGF has been proved to be reduced in eyes affected by dry eye [63] and has been proved to be effective in several corneal diseases such as neurotrophic keratitis, immune corneal ulcer, and HSV keratitis and after cataract surgery [64]. Clinical trials are ongoing to evaluate therapy with NGF eye drops in corneal diseases and first results seem to be very promising [65].

In addition, a conditioned medium derived from human uterine cervical stem cells has been tested for corneal epithelial healing [66], and a therapeutically ocular surface medium, routinely used to culture epithelial cells, was suggested as novel eye drops for DES and PED [67].

Among these emerging therapies, the use of biologic eye drops derived from both human peripheral [44, 50, 68-75] and umbilical cord blood serum [76-78] plays a crucial role in several corneal diseases. Previous in vitro experiments showed that corneal epithelial cell morphology and cell functions are better maintained by human serum eye drops (SE) than pharmaceutical tear substitutes [79].

The first applications of human SE to support corneal regeneration were performed in 1975 in corneal alkali injury cases [80]; later, in 1984, Fox et al. [81] reported the use of $\mathrm{SE}$ in a DES. Later, SE have gained a therapeutic dignity in ophthalmology as a new concept to manage wounded cornea $[82,83]$. To date, despite the fact that SE therapy could avoid drug side effects, its use is restricted and is not universally recognized as therapeutic option although several aspects of the whole regenerative medicine are still debated [11].

Here, we critically analyzed the current applications of SE in corneal diseases like DES and PED by focusing on crucial topics for its production and the current legislative restrictions in support of its use. To analyze the SE therapeutic achievement, we reported the most recent published randomized clinical trials (RTCs) and ongoing studies where this kind of treatment has been applied and compared to standard and other emergent treatments in severe ocular conditions.

\section{Legislative, Ethical, and Technical Implications on the Use of Serum Eye Drops}

The use of SE obtained from patient peripheral whole blood (autologous) or from healthy donor (nonautologous or allogenic) represents a biological therapeutic strategy influencing and promoting the corneal restitution $[11,68,83]$. The rationale for its use arises from its strong similarity to tears, in regard to $\mathrm{pH}(7.4)$ and osmolarity $(298 \mathrm{mml}$ for tears and $296 \mathrm{mml}$ for serum) [84] as well as its biochemical constitution. In addition, SE offer the same platelet derived antibacterial and anti-inflammatory effect in vivo [85].

Despite the fact that multiple studies supported the safety and efficacy of SE over standard treatments, SE have not yet been considered for approval by Food and Drug Administration, in the United States [8].

For this reason, $\mathrm{SE}$ are not a recognized treatment and are not covered by most of medical insurances [82]. In addition, despite the improved reliability of current serologic tests for HBs-Ag, anti-HCV, anti-HIV-1/2, and syphilis detection, the use of allogenic SE is associated with the immunologic and infectious implications of donor exposure [86]. However, even though autologous SE should be considered the best choice, patients with absolute contraindications to provide blood as a result of specific diseases or conditions (e.g., 
bacteremia) or who are unable to tolerate frequent venipunctures are eligible for the treatment with healthy donor SE. The allogenic SE, subjected to severe laboratory checks, can be used as an effective alternative treatment showing comparable clinical results to the autologous one $[73,86]$.

The established criteria for donor enrollment and for blood collection include hemoglobin level higher than $11 \mathrm{~g} / \mathrm{dL}$ (hematocrit $>33 \%$ ) and exclude subjects presenting risk of bacteremia and cardiovascular diseases deferring pregnant women and children. Despite the absence of absolute prohibitions, the use of SE in children is restricted to avoid repeated required venipunctures and limiting instillation of potentially infectious donor sera in such patients $[86,87]$. In these cases, if traditional therapy with artificial tears, antibiotics, or steroids is not effective, the topical cyclosporine or the conjunctival flap can be applied to improve the corneal conditions [87].

According to the current protocols, blood samples should be collected with previous informant consent and transferred into a sterile kit or blood bag without anticoagulant and treated under sterile conditions (laminar flow hood) (Table 2). A sufficient time has to be dedicated to the patient to illustrate properly the treatment and the need for repeated blood sampling. As shown in Table 2, the routine production of SE is frequently affected by the lack of recognized procedures $[11,85]$. However, the proper management, handling, and storage of final product are essential for the successful treatment avoiding side effects.

To date, many laboratory protocols have been published for SE production with variable dilutions of serum (from $20 \%$ to $100 \%$ ) and with differences in clotting phase, centrifugation time, and speed $[88,89]$ (Table 2). According to previous studies, clotting time is critical to obtain ideal concentrations of EGF, TGF- $\beta-1$, and fibronectin in the collected serum [85]. In addition, a proper serum dilution is recommended to reduce the antiproliferative effect of TGF- $\beta$ which results five times higher in human serum than in tears [85]. Usually, $0.9 \%$ sodium saline or balanced salt solutions are utilized as diluents and preservatives solutions are not usually added to decrease the risk of induced toxicity. For the lack of preservatives, microbial cultures as well as the antibiotic therapy are recommended [85]. Finally, to preserve the biologic activity, the SE should be frozen in blood banks at $-70^{\circ} \mathrm{C}$ until its use or at $-20^{\circ} \mathrm{C}$ for a month and protected from light to prevent the degradation of vitamin A (Table 2).

Depending on clinical conditions, the frequency of instillations of SE may go from every 15 minutes to two times per day; also the duration of the reported treatment widely ranged from 3 days to a maximum of 36 months. In most cases, the improvement appears after a brief period of therapy (from 1 to 4 weeks) [90]. Studies reported one case of corneal immunoglobulin deposition, scleral vasculitis, epithelial erosion, conjunctivitis, decreased corneal sensitivity, inflammatory response, infections, and an isolated case of mycosis [90]. Recently, to avoid immunity complications, Anitua et al. have characterized a plasma rich in GF without IgE and complement suggesting its use in autoimmune diseases [82]. Until now, the few published data on clinical complications associated with SE have demonstrated the safety of this therapy. However, limitations in published studies as discussed below are observed.

\section{Clinical Applications and Study Results}

As shown in Table 2, several studies investigated the role of SE treatment mostly in corneas affected by DES and PED.

Despite the fact that most of the authors found objective and subjective wellbeing after the treatment with SE, the comparison of clinical results is complex because data have been obtained from nonhomogeneous populations affected by several unrelated corneal diseases. In addition, the technical preparation of SE shows different dilutions obtained with different solutions, clotting phases, centrifugation forces, and time intervals, as well as different storage temperatures and times that can modify the final clinical outcomes and healing times as shown in Table 2.

Recent results have confirmed the efficacy of SE with respect to conventional therapy [91] in patients with severe DES or PED $[79,92]$ both by improving tear film stability and providing subjective comfort. Moreover, two recent prospective interventional studies [93, 94], on large cohorts of patients with PED treated with SE after ocular surgery, showed a significant or moderate improvement of delayed heal. In particular, Chen et al. [93] showed that 165 patients treated with $20 \%$ SE after penetrating keratoplasty drastically reduced postoperative PED when compared to patients that received artificial tears. In addition, Lekhanont et al. [94] evaluated SE for PED in 181 patients showing a high proportion (93.92\%) of complete corneal epithelialization in only 4 days with low rate of adverse reactions.

Case reports have been described about the use of SE in other corneal diseases like ocular graft versus host disease [95, 96], bullous keratopathy [97], fulminant bilateral Haemophilus influenzae keratitis [98], neurotrophic corneal ulcer [99], anterior tissue necrosis after porous orbital implant [41], and Mooren's ulcer [100]. In all these cases, SE allowed a complete corneal healing with an effective improvement of the clinical conditions.

Despite many promising results, some recent studies have questioned the validity of this treatment. A prospective cross-sectional study on 34 patients did not find that SE could be effective in secondary Sjogren's syndrome due to elevated serum proinflammatory cytokine levels [101]. Moreover, a single prospective study on 17 patients with DES demonstrated the short-term benefit of SE, which persisted up only to three months after the end of therapy [102]. In 2013, Pan et al. [36] performed a meta-analysis identifying four randomized clinical trials, which compared SE with artificial tear treatment or saline solutions in patients with Sjogren's syndrome-related DES, non-Sjogren's syndrome DES, and postoperative DES. In conclusion, they advocated the need of recognized measures to define subjective symptoms and to assess the real effect of SE therapy for DES [36]. The use of SE was compared in randomized trials to unconventional biologic therapies, which have gained a growing interest, such as umbilical cord blood serum (CBS) $[103,104]$ and amniotic membrane transplant [105]. CBS is collected from umbilical vein after fetal delivery, manipulated, and collected 


\begin{tabular}{|c|c|c|c|c|c|c|c|c|c|}
\hline 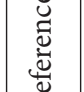 & $F$ & $\bar{\sigma}$ & $\underset{\Xi}{\Xi}$ & $\stackrel{\sqrt{\varrho}}{\varrho}$ & $\stackrel{\Omega}{\Xi}$ & a & $\bar{\alpha}$ & $\bar{\sigma}$ & $\stackrel{\infty}{\infty}$ \\
\hline 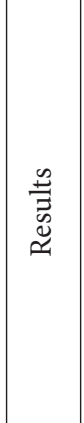 &  & 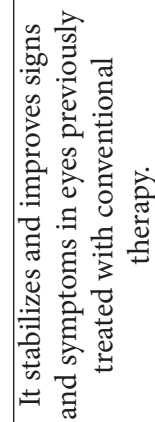 & 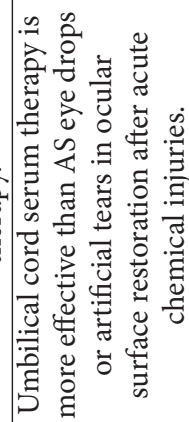 &  & 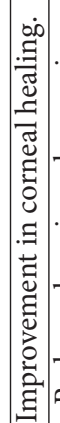 & 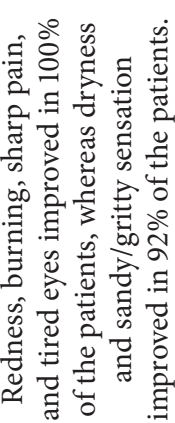 &  & 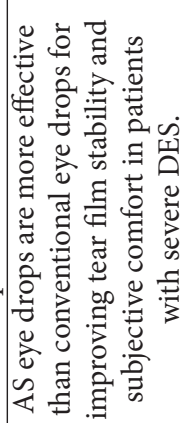 & 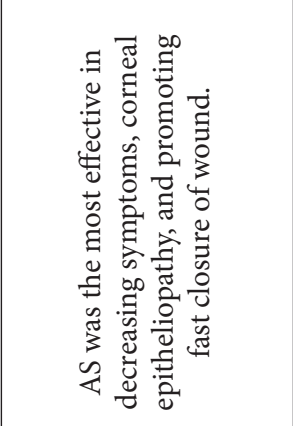 \\
\hline 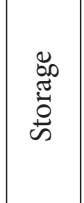 & 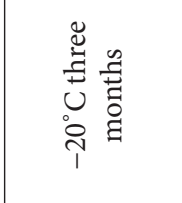 & 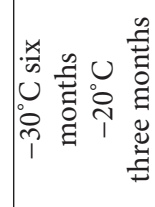 & 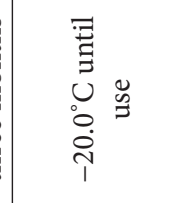 & 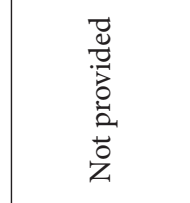 & $\begin{array}{l}0 \\
*++ \\
\end{array}$ & 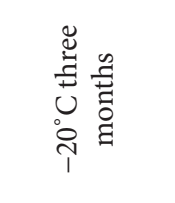 & $\begin{array}{l}0 \\
{ }^{u} \\
1\end{array}$ & $\begin{array}{l}0 \\
\stackrel{0}{1}\end{array}$ & 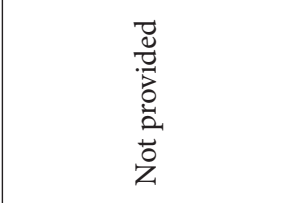 \\
\hline 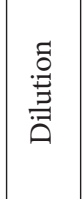 & 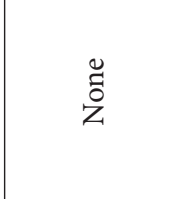 &  & 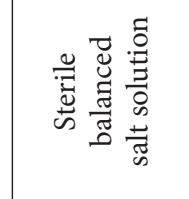 & 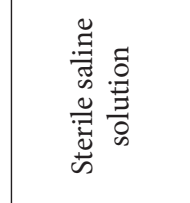 & $\mid \begin{array}{l}\Xi \\
\check{z} \\
z\end{array}$ & 艺 & 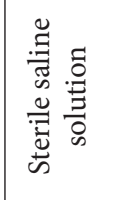 & 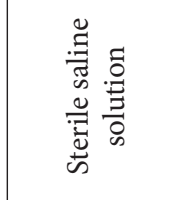 & 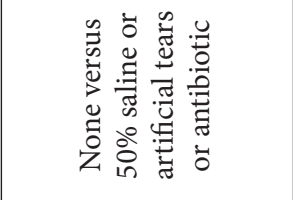 \\
\hline 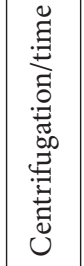 & 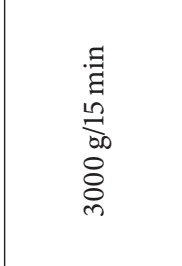 & 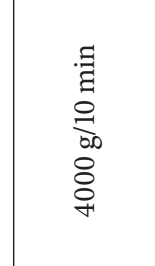 & 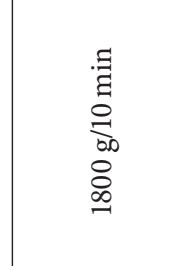 & 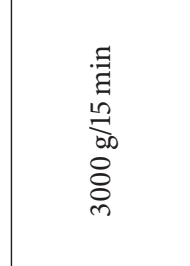 & 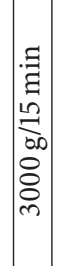 & 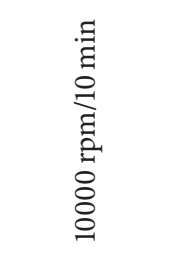 & 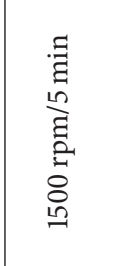 & 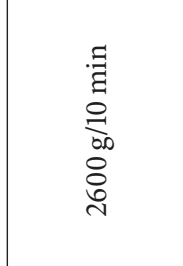 & 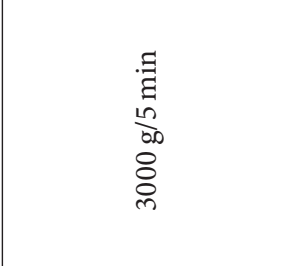 \\
\hline  & 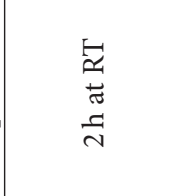 & 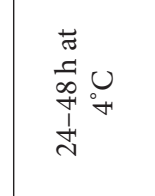 & 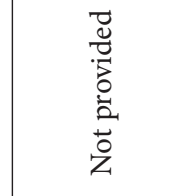 & $\stackrel{\Xi}{\sim}$ & $\mid$ & 气̊ & $\begin{array}{l}\text { 苜 } \\
\text { 号 }\end{array}$ & 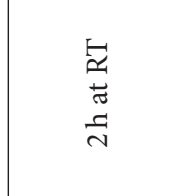 &  \\
\hline  & 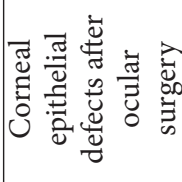 & 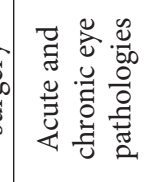 & 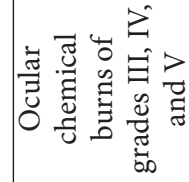 & 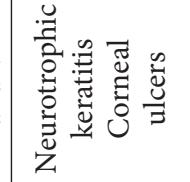 & 密 &  & 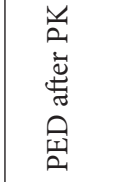 & 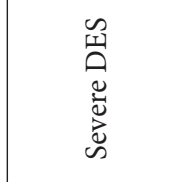 & 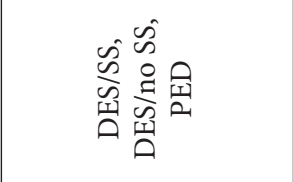 \\
\hline 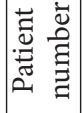 & 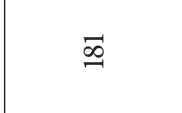 & $\stackrel{\infty}{\sim}$ & $m$ & F & 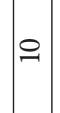 & $\stackrel{12}{n}$ & $\underline{2}$ & 우 & $\infty$ \\
\hline 䒕 & त् & 芯 & تี & 芯 & 岕 & تี & 윰 & ت্ّ & त् \\
\hline 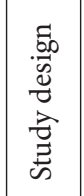 & 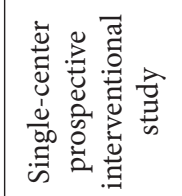 & 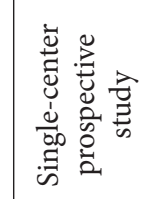 & 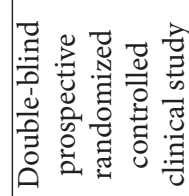 & 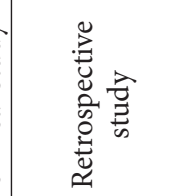 & 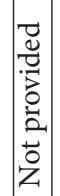 & 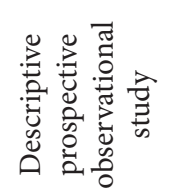 &  & 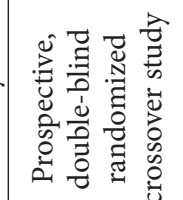 & 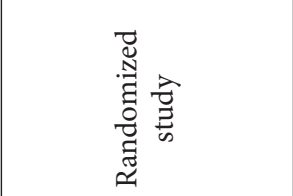 \\
\hline 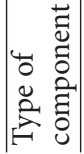 & 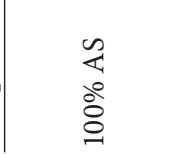 & $\begin{array}{l}\text { 足 } \\
\text { oे } \\
\text { iे }\end{array}$ & 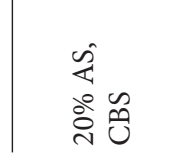 & 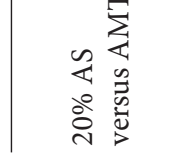 & 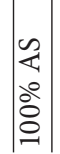 & 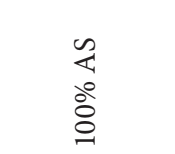 & 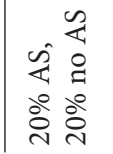 & $\begin{array}{l}\text { से } \\
\text { oें }\end{array}$ & 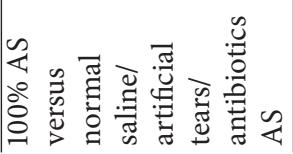 \\
\hline
\end{tabular}




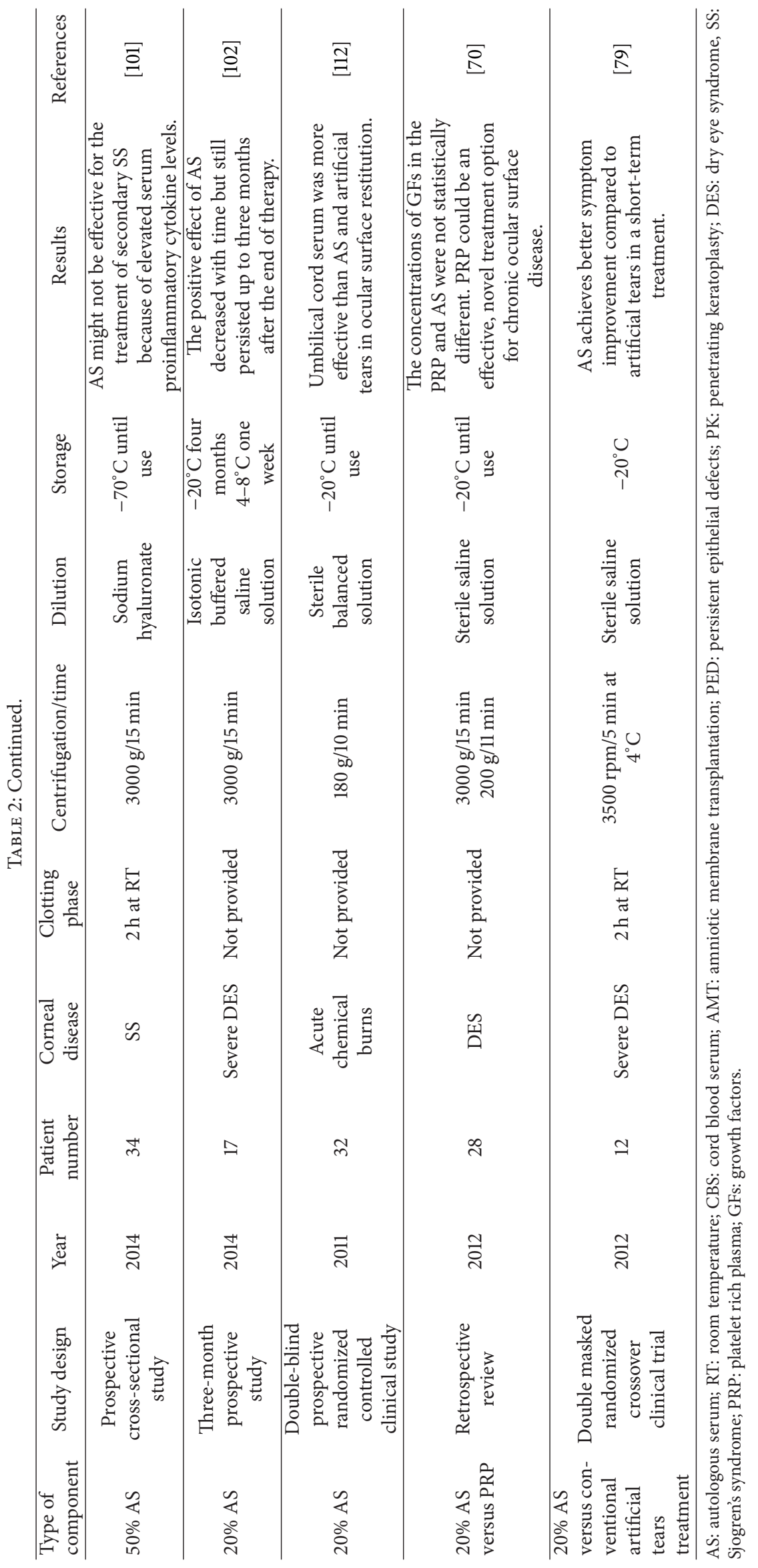


similarly to peripheral serum [104]. CBS is considered a reliable source of undifferentiated mesenchymal stem cells $[106,107]$, which are self-renewal elements that are able to replace directly corneal keratocytes [104] and conjunctival, limbal [76], and retinal nerve cells [104]. In addition, CBS contains consistent levels of cytokines, GFs, fibronectin, prealbumin, and fatty oils that provide useful instruments for corneal differentiation [74, 108]. Moreover, CBS includes antibacterial agents as IgG, lysozyme, and complement but lower levels of vitamin A compared to peripheral serum [109]. Despite the reduced immunogenicity of CBS with respect to peripheral serum due to the lower levels of IgM anti-A, anti$\mathrm{B}$, and IgG2 $[78,107]$, the use of the first is naturally associated to donor exposure and increased infectious risk and subjected to obstetric factors which could modify GF levels [110].

Some authors tested CBS for PED [77, 103], DES [111], corneal diseases due to chemical burns [112], and surgeries associated [113, 114]. Due to prominent GFs, antiinflammatory cytokines, and mesenchymal stem cell levels in CBS, some authors demonstrated the main effectiveness of CBS with respect to both conventional treatment and traditional SE in severe corneal diseases [77, 104, 109, 112]. For this reason, clinical ongoing trials are mostly focused on the comparative evaluation of the use of SE and CBS, especially in DES, PED, and ocular GVHD as summarized in Table 3. In six ongoing studies reported on CBS eye drops, four are comparing CBS versus traditional SE and only one study analyzes amniotic membrane transplant versus SE in 180 patients with PED. Probably, promising results will arise from a large cohort randomized intervention single blind study which has enrolled 165 patients with diabetic retinopathy and penetrating keratoplasty comparing SE with standard treatments like corticosteroids and antibiotics. To date, there are no follow-up studies on SE or CBS eye drops treatment.

\section{Future Directions}

Several fields of medicine are focusing on a regenerative approach to treat pathologic conditions affected by insensitivity and toxic reactions to standard therapies. In this context, tissue engineering and regenerative medicine are the present and the future aim of clinical therapy, especially where traditional treatments fail or promote severe adverse events.

A number of corneal conditions are often not fully managed by standard treatments and are characterized by intolerances and systemic effects. New treatments have to be considered. Subjective and objective results suggest that biologic therapies for corneal surface alterations like SE treatment could be an effective option. Indeed, the use of biologic eye drops provides the beneficial effects of vitamins, GFs, and cytokines by correcting delayed corneal healing pathways and by restoring balanced mechanisms $[76,78,79]$.

However, the technical preparation of human serum for ocular instillation should require a well-equipped laboratory with specialized trained personnel as well as the respect of aseptic and quality procedures. In addition, methods for SE production (clotting time, centrifugation, and concentration) including the proper additive and GF doses should be optimized according to well-established guidelines and standardized quality controlled protocols $[9,36,111]$. Specifically, a proper serum dilution should be performed to reduce the TGF $\beta 1 / \beta 2$ levels (present in more than 5 times in serum compared to tears), which would promote corneal scar formations and a delayed reepithelialization (Table 1) [113]. Additionally, informed consent should be obtained from each patient in case of allogenic somministration to avoid ethical and juridical implications owing to blood transfusion practices and legislative restrictions should be carefully respected to minimize the immunological and infectious risks [11, 84].

\section{Conclusions}

To date, clinical benefits of SE therapy have been demonstrated by some published studies. Most of the recent analyzed trials have tested the clinical results coming from SE treatment through the comparison with traditional therapeutic approaches such as artificial tears, antibiotics, or corticosteroids [79, 91, 92]. Several randomized studies suggest that SE treatment leads to an improved tear film stability and subjective comfort $[29,69,83,88,91,93,94]$ by determining a faster epithelial healing time and a better corneal transparency without increase of vascularization or fibrosis. Moreover, several data have confirmed the safety and the almost absolute absence of toxic and side effects, especially in severe case of DES or in PED (except those related to an improper handling). A critical point of these published studies concerns the number of patients enrolled which are recurrently less than $100[4,13,16,35,38,39$, $43,84,85,95,96]$ and the almost absence of long followup studies [69]. On the other hand, the evaluation of the ongoing studies on this therapy showed that the newer fields of clinical research are focusing on alternatives to SE like CBS. In this regard, many studies are testing CBS and its therapeutic properties and safety. However, further studies with large populations comparing biological therapies with the traditional ones in corneal diseases are needed to provide the best treatment tailored to the singular patient.

Forthcoming conclusions will guide future efforts useful to clinical advances. They will clarify the therapeutic limits and resources of these emergent biologic therapies for corneal surface alterations, especially for refractory patients.

\section{Method of Literature Search}

We performed a computerized literature search on studies and trials by using the following search terms in various combinations: serum eye drops, cord blood serum, dry eye, and persistent epithelial defects. This search was achieved without any time and language restrictions in the following databases: PubMed, http://www.controlled-trials.com/, https ://www.clinicaltrialsregister.eu/, https://eudract.ema.europa .eu/, and https://www.clinicaltrials.gov/. The complete reference list of the most relevant studies was compared for the methodology of serum eye drops collection, preparation, and 







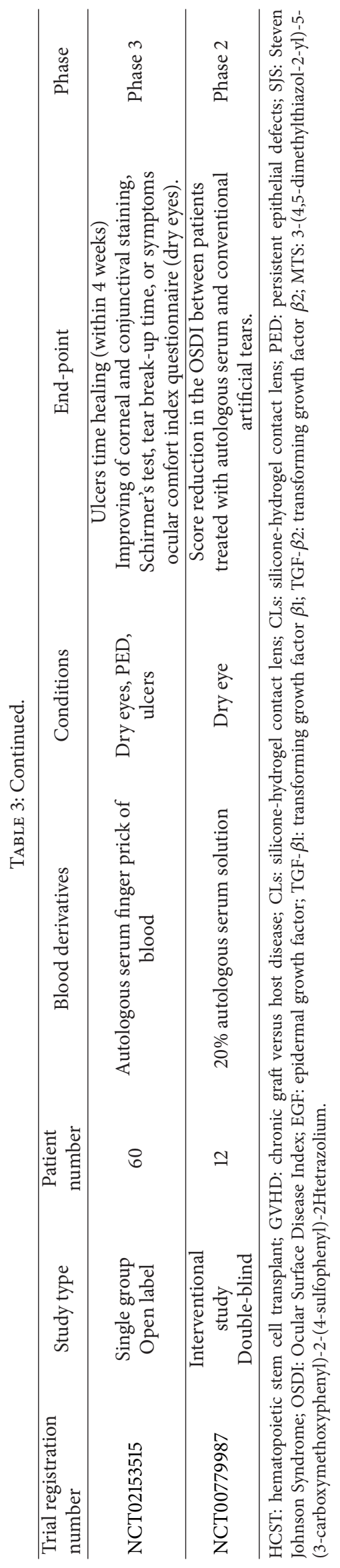


storage. Clinical trials reported in Table 2 were selected from studies published in the last 5 years (2010-2014).

\section{Conflict of Interests}

The authors have no financial interests with any concept material or devices listed in this paper.

\section{Authors' Contribution}

Maria Rosaria De Pascale and Michele Lanza equally contributed to this work.

\section{Acknowledgment}

The authors would like to acknowledge Dr. Maria Vasco for illustrations (Figure 1).

\section{References}

[1] T. Lai and S. Tang, "Cornea characterization using a combined multiphoton microscopy and optical coherence tomography system," Biomedical Optics Express, vol. 5, no. 5, pp. 1494-1511, 2014.

[2] J.-H. Chang, N. K. Garg, E. Lunde, K.-Y. Han, S. Jain, and D. T. Azar, "Corneal neovascularization: an Anti-VEGF therapy review," Survey of Ophthalmology, vol. 57, no. 5, pp. 415-429, 2012.

[3] N. C. Joyce, "Cell cycle status in human corneal endothelium," Experimental Eye Research, vol. 81, no. 6, pp. 629-638, 2005.

[4] B. Czarkowska-Paczek, I. Bartlomiejczyk, and J. Przybylski, "The serum levels of growth factors: PDGF, TGF-beta and VEGF are increased after strenuous physical exercise," Journal of Physiology and Pharmacology, vol. 57, no. 2, pp. 189-197, 2006.

[5] I. Flisiak, M. Szterling-Jaworowska, A. Baran, and M. RogalskaTaranta, "Effect of psoriasis activity on epidermal growth factor (EGF) and the concentration of soluble EGF receptor in serum and plaque scales," Clinical and Experimental Dermatology, vol. 39, no. 4, pp. 461-467, 2014.

[6] R. Kucera, I. Treskova, J. Vrzalova et al., "Evaluation of IGF1 serum levels in malignant melanoma and healthy subjects," Anticancer Research, vol. 34, no. 9, pp. 5217-5220, 2014.

[7] P. Blair and R. Flaumenhaft, "Platelet alpha-granules: basic biology and clinical correlates," Blood Reviews, vol. 23, no. 4, pp. 177-189, 2009.

[8] J. Imanishi, K. Kamiyama, I. Iguchi, M. Kita, C. Sotozono, and S. Kinoshita, "Growth factors: importance in wound healing and maintenance of transparency of the cornea," Progress in Retinal and Eye Research, vol. 19, no. 1, pp. 113-129, 2000.

[9] J. K. Lee and T. H. Kim, "Changes in cytokines in tears after endoscopic endonasal dacryocystorhinostomy for primary acquired nasolacrimal duct obstruction," Eye, vol. 28, no. 5, pp. 600-607, 2014.

[10] T. L. Moskal, S. Huang, L. M. Ellis, H. A. Fritsche Jr., and S. Chakrabarty, "Serum levels of transforming growth factor alpha in gastrointestinal cancer patients," Cancer Epidemiology Biomarkers and Prevention, vol. 4, no. 2, pp. 127-131, 1995.

[11] M. R. De Pascale, L. Sommese, A. Casamassimi, and C. Napoli, "Platelet derivatives in regenerative medicine: an update," Transfusion Medicine Reviews, vol. 29, no. 1, pp. 52-61, 2015.
[12] J.-P. Montmayeur, M. Valius, J. Vandenheede, and A. Kazlauskas, "The platelet-derived growth factor beta receptor triggers multiple cytoplasmic signaling cascades that arrive at the nucleus as distinguishable inputs," The Journal of Biological Chemistry, vol. 272, no. 51, pp. 32670-32678, 1997.

[13] J. Schechter, M. Wallace, J. Carey, N. Chang, M. Trousdale, and R. Wood, "Corneal insult affects the production and distribution of FGF-2 within the lacrimal gland," Experimental Eye Research, vol. 70, no. 6, pp. 777-784, 2000.

[14] E. Anitua, M. Sanchez, J. Merayo-Lloves, M. de La Fuente, F. Muruzabal, and G. Orive, "Plasma rich in growth factors (PRGF-Endoret) stimulates proliferation and migration of primary keratocytes and conjunctival fibroblasts and inhibits and reverts TGF- $\beta 1$-induced myodifferentiation," Investigative Ophthalmology \& Visual Science, vol. 52, no. 9, pp. 6066-6073, 2011.

[15] M. E. Fini and B. M. Stramer, "How the cornea heals: cornea-specific repair mechanisms affecting surgical outcomes," Cornea, vol. 24, supplement 8, pp. S2-S11, 2005.

[16] J. L. Peterson, E. D. Phelps, M. A. Doll, S. Schaal, and B. P. Ceresa, "The role of endogenous epidermal growth factor receptor ligands in mediating corneal epithelial homeostasis," Investigative Ophthalmology and Visual Science, vol. 55, no. 5, pp. 2870-2880, 2014.

[17] F. Castro-Muñozledo, "Review: corneal epithelial stem cells, their niche and wound healing," Molecular Vision, vol. 24, no. 19, pp. 1600-1613, 2013.

[18] Q. Li, J. Weng, R. R. Mohan et al., "Hepatocyte growth factor and hepatocyte growth factor receptor in the lacrimal gland, tears, and cornea," Investigative Ophthalmology \& Visual Science, vol. 37, no. 5, pp. 727-739, 1996.

[19] K. S. Park, S. S. Kim, J. C. Kim et al., "Serum and tear levels of nerve growth factor in diabetic retinopathy patients," American Journal of Ophthalmology, vol. 145, no. 3, pp. 432-437, 2008.

[20] G. B. van Setten, S. Macauley, M. Humphreys-Beher et al., "Detection of transforming growth factor-alpha mRNA and protein in rat lacrimal glands and characterization of transforming growth factor-alpha in human tears," Journal of Physiology and Pharmacology, vol. 57, no. 2, pp. 189-197, 2006.

[21] G. B. van Setten, "Basic fibroblast growth factor in human tear fluid: detection of another growth factor," Graefe's Archive for Clinical and Experimental Ophthalmology, vol. 234, no. 4, pp. 275-277, 1996.

[22] M. Vesaluoma, A. M. Teppo, C. Grönhagen-Riska et al., "Platelet-derived growth factor-BB (PDGF-BB) in tear fluid: a potential modulator of corneal wound healing following photorefractive keratectomy," Investigative Ophthalmology \& Visual Science, vol. 37, no. 1, pp. 166-173, 1996.

[23] S. E. Wilson and H. D. Perry, "Long-term resolution of chronic dry eye symptoms and signs after topical cyclosporine treatment," Ophthalmology, vol. 114, no. 1, pp. 76-79, 2007.

[24] K. Yoshino, R. Garg, D. Monroy, Z. Ji, and S. C. Pflugfelder, "Production and secretion of transforming growth factor beta (TGF- $\beta$ ) by the human lacrimal gland," Current Eye Research, vol. 15, no. 6, pp. 615-624, 1996.

[25] B. Klenkler, H. Sheardown, and L. Jones, "Growth factors in the tear film: role in tissue maintenance, wound healing, and ocular pathology," Ocular Surface, vol. 5, no. 3, pp. 228-239, 2007.

[26] L. R. Katzman and B. H. Jeng, "Management strategies for persistent epithelial defects of the cornea," Saudi Journal of Ophthalmology, vol. 28, no. 3, pp. 168-172, 2014. 
[27] C. Cursiefen, "Dry eye," Der Ophthalmologe, vol. 110, no. 6, pp. 498-499, 2013.

[28] M. Hessen and E. K. Akpek, "Dry eye: an inflammatory ocular disease," Journal of Ophthalmic \& Vision Research, vol. 9, no. 2, pp. 240-250, 2014.

[29] M. M. Choudhary, R. A. Hajj-Ali, and C. Y. Lowder, "Gender and ocular manifestations of connective tissue diseases and systemic vasculitides," Journal of Ophthalmology, vol. 2014, Article ID 403042, 8 pages, 2014.

[30] C. F. Henrich, P. Y. Ramulu, and E. K. Akpek, "Association of dry eye and inflammatory systemic diseases in a tertiary care-based sample," Cornea, vol. 33, no. 8, pp. 819-825, 2014.

[31] M. C. Moura, P. T. S. Zakszewski, M. B. G. Silva, and T. L. Skare, "Epidemiological profile of patients with extra-articular manifestations of rheumatoid arthritis from the city of Curitiba, south of Brazil," Revista Brasileira de Reumatologia, vol. 52, no. 5, pp. 679-694, 2012.

[32] S. J. Patel and D. C. Lundy, "Ocular manifestations of autoimmune disease," American Family Physician Journal, vol. 66, no. 6, pp. 991-998, 2002.

[33] K. A. Beckman, "Detection of early markers for Sjögren syndrome in dry eye patients," Cornea, vol. 33, no. 12, pp. 1262-1264, 2014.

[34] V. Achtsidis, I. Eleftheriadou, E. Kozanidou et al., "Dry eye syndrome in subjects with diabetes and association with neuropathy," Diabetes Care, vol. 37, no. 10, pp. e210-e211, 2014.

[35] B. Yañez-Soto, M. J. Mannis, I. R. Schwab et al., "Interfacial phenomena and the ocular surface," Ocular Surface, vol. 12, no. 3, pp. 178-201, 2014.

[36] Q. Pan, A. Angelina, A. Zambrano et al., "Autologous serum eye drops for dry eye," The Cochrane Database of Systematic Reviews, vol. 8, Article ID CD009327, 2013.

[37] C. G. Begley, R. L. Chalmers, L. Abetz et al., “The relationship between habitual patient-reported symptoms and clinical signs among patients with dry eye of varying severity," Investigative Ophthalmology \& Visual Science, vol. 44, no. 11, pp. 4753-4761, 2003.

[38] M. S.-B. Zeev, D. D. Miller, and R. Latkany, "Diagnosis of dry eye disease and emerging technologies," Clinical Ophthalmology, vol. 8, pp. 581-590, 2014.

[39] B. D. Sullivan, L. A. Crews, E. M. Messmer et al., "Correlations between commonly used objective signs and symptoms for the diagnosis of dry eye disease: clinical implications," Acta Ophthalmologica, vol. 92, no. 2, pp. 161-166, 2014.

[40] M. Dogru and K. Tsubota, "Pharmacotherapy of dry eye," Expert Opinion on Pharmacotherapy, vol. 12, no. 3, pp. 325-334, 2011.

[41] J. Hefner and H. Reinshagen, "Conservative treatment of dry eye," Klinische Monatsblätter für Augenheilkunde, vol. 231, no. 11, pp. 1093-1096, 2014.

[42] V. Valim, V. F. M. Trevisani, J. M. de Sousa, V. S. Vilela, and R. Belfort Jr., "Current approach to dry eye disease," Clinical Reviews in Allergy \& Immunology, 2014.

[43] R. R. Pfister, "Clinical measures to promote corneal epithelial healing." Acta Ophthalmologica Supplement, vol. 202, pp. 7383, 1992.

[44] K. Tsubota, "Ocular surface treatment before last in situ keratomileusis in patients with severe dry eye," Journal of Refractive Surgery, vol. 20, no. 3, pp. 270-275, 2004.

[45] T. G. Coursey and C. S. de Paiva, "Managing Sjögren's syndrome and non-Sjögren syndrome dry eye with anti-inflammatory therapy," Clinical Ophthalmology, vol. 8, pp. 1447-1458, 2014.
[46] B. Colligris, A. Crooke, F. Huete-Toral, and J. Pintor, "An update on dry eye disease molecular treatment: advances in drug pipelines," Expert Opinion on Pharmacotherapy, vol. 15, no. 10, pp. 1371-1390, 2014.

[47] S. Schrader, T. Wedel, R. Moll, and G. Geerling, "Combination of serum eye drops with hydrogel bandage contact lenses in the treatment of persistent epithelial defects," Graefe's Archive for Clinical and Experimental Ophthalmology, vol. 244, no. 10, pp. 1345-1349, 2006.

[48] K.-Y. Wu, H.-Z. Wang, and S.-J. Hong, "Effects of antibiotics and corticosteroid eyedrops on cellular proliferation in cultured human corneal keratocytes," The Kaohsiung Journal of Medical Sciences, vol. 22, no. 8, pp. 385-389, 2006.

[49] S. Shi, W. Chen, X. Zhang, H.-X. Ma, and L. Sun, "Effects of silicone punctal plugs for tear deficiency dry eye patients," Chinese Journal of Ophthalmology, vol. 49, no. 2, pp. 151-154, 2013.

[50] A.-M. Ervin, R. Wojciechowski, and O. Schein, "Punctal occlusion for dry eye syndrome," Cochrane Database of Systematic Reviews, no. 9, Article ID CD006775, 2010.

[51] A. A. Bukhari, "Botulinum neurotoxin type A versus punctal plug insertion in the management of dry eye disease," Oman Journal of Ophthalmology, vol. 7, no. 2, pp. 61-65, 2014.

[52] A. Liu and J. Ji, "Omega-3 essential fatty acids therapy for dry eye syndrome: a meta-analysis of randomized controlled studies," Medical Science Monitor, vol. 20, pp. 1583-1589, 2014.

[53] A. Oleñik, "Effectiveness and tolerability of dietary supplementation with a combination of omega-3 polyunsaturated fatty acids and antioxidants in the treatment of dry eye symptoms: results of a prospective study," Clinical Ophthalmology, vol. 8, pp. 169-176, 2014.

[54] E. Toker and E. Asfuroğlu, "Corneal and conjunctival sensitivity in patients with dry eye: the effect of topical cyclosporine therapy," Cornea, vol. 29, no. 2, pp. 133-140, 2010.

[55] A. A. M. Torricelli, M. R. Santhiago, and S. E. Wilson, "Topical cyclosporine A treatment in corneal refractive surgery and patients with dry eye," Journal of Refractive Surgery, vol. 30, no. 8, pp. 558-564, 2014.

[56] N. P. Walsh, M. B. Fortes, P. Raymond-Barker et al., "Is whole-body hydration an important consideration in dry eye?" Investigative Ophthalmology \& Visual Science, vol. 53, no. 10, pp. 6622-6627, 2012.

[57] S. E. Wilson, Q. Liang, and W. J. Kim, "Lacrimal gland HGF, KGF, and EGF mRNA levels increase after corneal epithelial wounding," Investigative Ophthalmology \& Visual Science, vol. 37, no. 5, pp. 727-739, 1996.

[58] F. N. Syed-Picard, Y. Du, K. L. Lathrop, M. M. Mann, M. L. Funderburgh, and J. L. Funderburgh, "Dental pulp stem cells: a new cellular resource for corneal stromal regeneration," Stem Cells Translational Medicine, vol. 4, no. 3, pp. 276-285, 2015.

[59] M. H. Frank and N. Y. Frank, "Restoring the cornea from Limbal stem cells," Regenerative Medicine, vol. 10, no. 1, pp. 1-4, 2015.

[60] S. Rauz and V. P. Saw, "Serum eye drops, amniotic membrane and limbal epithelial stem cells-tools in the treatment of ocular surface disease," Cell and Tissue Banking, vol. 11, no. 1, pp. 13-27, 2010.

[61] J. M. Lou-Bonafonte, E. Bonafonte-Marquez, S. BonafonteRoyo, and P. A. Martínez-Carpio, "Posology, efficacy, and safety of epidermal growth factor eye drops in 305 patients: logistic regression and group-wise odds of published data," Journal of Ocular Pharmacology and Therapeutics, vol. 28, no. 5, pp. 467472, 2012. 
[62] A. Lambiase, L. Aloe, F. Mantelli et al., "Capsaicin-induced corneal sensory denervation and healing impairment are reversed by NGF treatment," Investigative Ophthalmology \& Visual Science, vol. 53, no. 13, pp. 8280-8287, 2012.

[63] A. Lambiase, A. Micera, M. Sacchetti, M. Cortes, F. Mantelli, and S. Bonini, "Alterations of tear neuromediators in dry eye disease," Archives of Ophthalmology, vol. 129, no. 8, pp. 981-986, 2011.

[64] A. Lambiase, M. Sacchetti, and S. Bonini, "Nerve growth factor therapy for corneal disease," Current Opinion in Ophthalmology, vol. 23, no. 4, pp. 296-302, 2012.

[65] M. P. Ferrari, F. Mantelli, M. Sacchetti et al., "Safety and pharmacokinetics of escalating doses of human recombinant nerve growth factor eye drops in a double-masked, randomized clinical trial," BioDrugs, vol. 28, no. 3, pp. 275-283, 2014.

[66] M. A. Bermudez, J. Sendon-Lago, N. Eiro et al., "Corneal epithelial wound healing and bactericidal effect of conditioned medium from human uterine cervical stem cells," Investigative Ophthalmology \& Visual Science, vol. 56, no. 2, pp. 983-992, 2015.

[67] S. L. Watson, G. Geerling, and J. K. G. Dart, "Clinical study of therapeutic ocular surface medium for persistent epithelial defect," Ophthalmic Research, vol. 51, no. 2, pp. 82-87, 2014.

[68] A. A. Azari and C. J. Rapuano, "Autologous serum eye drops for the treatment of ocular surface disease," Eye \& Contact Lens, vol. 41, no. 3, pp. 133-140, 2015.

[69] A. J. Botella, J. F. M. Peiró, K. Márques, N. M. Cambero, and J. S. Otaolaurruchi, "Effectiveness of $100 \%$ autologous serum drops in ocular surface disorders," Farmacia Hospitalaria, vol. 35, no. 1, pp. 8-13, 2011.

[70] K. M. Kim, Y.-T. Shin, and H. K. Kim, "Effect of autologous platelet-rich plasma on persistent corneal epithelial defect after infectious keratitis," Japanese Journal of Ophthalmology, vol. 56, no. 6, pp. 544-550, 2012.

[71] T. Kojima, R. Ishida, M. Dogru et al., "The effect of autologous serum eyedrops in the treatment of severe dry eye disease: a prospective randomized case-control study," American Journal of Ophthalmology, vol. 139, no. 2, pp. 242-246, 2005.

[72] Y. Matsumoto, M. Dogru, E. Goto et al., "Autologous serum application in the treatment of neurotrophic keratopathy," Ophthalmology, vol. 111, no. 6, pp. 1115-1120, 2004.

[73] K.-S. Na and M. S. Kim, "Allogeneic serum eye drops for the treatment of dry eye patients with chronic graft-versus-host disease," Journal of Ocular Pharmacology and Therapeutics, vol. 28, no. 5, pp. 479-483, 2012.

[74] S. Kamal, S. Kumar, and R. Goel, "Autologous serum for anterior tissue necrosis after porous orbital implant," Middle East African Journal of Ophthalmology, vol. 21, no. 2, pp. 193-195, 2014.

[75] S. D. Schulze, W. Sekundo, and P. Kroll, "Autologous serum for the treatment of corneal epithelial abrasions in diabetic patients undergoing vitrectomy," American Journal of Ophthalmology, vol. 142, no. 2, pp. 207-211, 2006.

[76] L. P.-K. Ang, T. P. Do, Z. M. Thein et al., "Ex vivo expansion of conjunctival and limbal epithelial cells using cord blood serumsupplemented culture medium," Investigative Ophthalmology \& Visual Science, vol. 52, no. 9, pp. 6138-6147, 2011.

[77] E. Erdem, M. Yagmur, I. Harbiyeli, H. Taylan-Sekeroglu, and R. Ersoz, "Umbilical cord blood serum therapy for the management of persistent corneal epithelial defects," International Journal of Ophthalmology, vol. 18, no. 5, pp. 807-810, 2014.
[78] H. M. Reza, B.-Y. Ng, F. L. Gimeno, T. T. Phan, and L. P.-K. Ang, "Umbilical cord lining stem cells as a novel and promising source for ocular surface regeneration," Stem Cell Reviews and Reports, vol. 7, no. 4, pp. 935-947, 2011.

[79] C. A. Urzua, D. H. Vasquez, A. Huidobro, H. Hernandez, and J. Alfaro, "Randomized double-blind clinical trial of autologous serum versus artificial tears in dry eye syndrome," Current Eye Research, vol. 37, no. 8, pp. 684-688, 2012.

[80] R. A. Ralph, M. G. Doane, and C. H. Dohlman, "Clinical experience with a mobile ocular perfusion pump," Archives of Ophthalmology, vol. 93, no. 10, pp. 1039-1043, 1975.

[81] R. I. Fox, R. Chan, J. B. Michelson, J. B. Belmont, and P. E. Michelson, "Beneficial effect of artificial tears made with autologous serum in patients with keratoconjunctivitis sicca," Arthritis \& Rheumatism, vol. 27, no. 4, pp. 459-461, 1984.

[82] E. Anitua, F. Muruzabal, M. De la Fuente, J. Merayo-Lloves, and G. Orive, "Effects of heat-treatment on plasma rich in growth factors-derived autologous eye drop," Experimental Eye Research, vol. 119, pp. 27-34, 2014.

[83] B. H. Jeng and W. J. Dupps Jr., "Autologous serum 50\% eye drops in the treatment of persistent corneal epithelial defects," Cornea, vol. 28, no. 10, pp. 1104-1108, 2009.

[84] A. Partal and E. Scott, "Low-cost protocol for the production of autologous serum eye drops by blood collection and processing centres for the treatment of ocular surface diseases," Transfusion Medicine, vol. 21, no. 4, pp. 271-277, 2011.

[85] H. R. Lee, Y. J. Hong, S. Chung et al., "Proposal of standardized guidelines for the production and quality control of autologous serum eye drops in Korea: based on a nationwide survey," Transfusion, vol. 54, no. 7, pp. 1864-1870, 2014.

[86] C.-C. Chiang, J.-M. Lin, W.-L. Chen, and Y.-Y. Tsai, "Allogeneic serum eye drops for the treatment of severe dry eye in patients with chronic graft-versus-host disease," Cornea, vol. 26, no. 7, pp. 861-863, 2007.

[87] F. M. C. Medina, R. S. de Castro, S. C. Leite, E. M. Rocha, and G. D. M. Rocha, "Management of dry eye related to systemic diseases in childhood and longterm follow-up," Acta Ophthalmologica Scandinavica Journal, vol. 85, no. 7, pp. 739-744, 2007.

[88] Y. K. Cho, W. Huang, G. Y. Kim, and B. S. Lim, "Comparison of autologous serum eye drops with different diluents," Current Eye Research, vol. 38, no. 1, pp. 9-17, 2013.

[89] J. S. Lõpez-García, I. García-Lozano, L. Rivas, N. Ramírez, R. Raposo, and M. T. Méndez, "Autologous serum eye drops diluted with sodium hyaluronate: clinical and experimental comparative study," Acta Ophthalmologica, vol. 92, no. 1, pp. e22-e29, 2014.

[90] C. Yamada, K. E. King, and P. M. Ness, "Autologous serum eyedrops: literature review and implications for transfusion medicine specialists," Transfusion, vol. 48, no. 6, pp. 1245-1255, 2008.

[91] F. Semeraro, E. Forbice, O. Braga, A. Bova, A. Di Salvatore, and C. Azzolini, "Evaluation of the efficacy of $50 \%$ autologous serum eye drops in different ocular surface pathologies," BioMed Research International, vol. 2014, Article ID 826970, 11 pages, 2014.

[92] A. R. C. Celebi, C. Ulusoy, and G. E. Mirza, "The efficacy of autologous serum eye drops for severe dry eye syndrome: a randomized double-blind crossover study," Graefe's Archive for Clinical and Experimental Ophthalmology, vol. 252, no. 4, pp. 619-626, 2014.

[93] Y.-M. Chen, F.-R. Hu, J.-Y. Huang, E. P. Shen, T.-Y. Tsai, and W.-L. Chen, "The effect of topical autologous serum on graft 
re-epithelialization after penetrating keratoplasty," American Journal of Ophthalmology, vol. 150, no. 3, pp. 352.e2-359.e2, 2010.

[94] K. Lekhanont, P. Jongkhajornpong, L. Choubtum, and V. Chuckpaiwong, "Topical $100 \%$ serum eye drops for treating corneal epithelial defect after ocular surgery," BioMed Research International, vol. 2013, Article ID 521315, 7 pages, 2013.

[95] A. I. Fernando, B. J. L. Burton, G. T. Smith, and M. C. Corbett, "Autologous serum drop-dependent re-epithelialisation following penetrating keratoplasty in chronic graft vs host disease," Eye, vol. 19, no. 7, pp. 823-825, 2005.

[96] B. Mixon, J. Mixon, E. K. Isbey et al., "Autologous serum eye drops for severe dry eye syndrome in a patient with chronic graft-versus-host disease: a case report," International Journal of Pharmaceutical Compounding, vol. 18, no. 5, pp. 370-377, 2014.

[97] A. Mataftsi, A. Bourtoulamaiou, K. Anastasilakis, N. G. Ziakas, and S. A. Dimitrakos, "Management of bullous keratopathyrelated ulcer with autologous serum," Eye \& Contact Lens, vol. 39, no. 4, pp. e19-e20, 2013.

[98] E. Sanz-Marco, M. J. Lopez-Prats, S. Garcia-Delpech, P. Udaondo, and M. Diaz-Llopis, "Fulminant bilateral Haemophilus influenzae keratitis in a patient with hypovitaminosis A treated with contaminated autologous serum," Clinical Ophthalmology, vol. 11, no. 5, pp. 71-73, 2011.

[99] S.-W. Moon, D.-J. Yeom, and S.-H. Chung, "Neurotrophic corneal ulcer development following cataract surgery with a limbal relaxing incision," Korean Journal of Ophthalmology, vol. 25, no. 3, pp. 210-213, 2011.

[100] P. Lavaju, M. Sharma, A. Sharma, and S. Chettri, "Use of amniotic membrane and autologous serum eye drops in Mooren's ulcer," Nepalese Journal of Ophthalmology, vol. 5, no. 1, pp. 120123, 2013.

[101] J. Hwang, S.-H. Chung, S. Jeon, S.-K. Kwok, S.-H. Park, and M.S. Kim, "Comparison of clinical efficacies of autologous serum eye drops in patients with primary and secondary Sjögren syndrome," Cornea, vol. 33, no. 7, pp. 663-667, 2014.

[102] K. Jirsova, K. Brejchova, I. Krabcova et al., "The application of autologous serum eye drops in severe dry eye patients; subjective and objective parameters before and after treatment," Current Eye Research, vol. 39, no. 1, pp. 21-30, 2014.

[103] R. B. Vajpayee, N. Mukerji, R. Tandon et al., "Evaluation of umbilical cord serum therapy for persistent corneal epithelial defects," British Journal of Ophthalmology, vol. 87, no. 11, pp. 1312-1316, 2003.

[104] K. C. Yoon, "Use of umbilical cord serum in ophthalmology," Chonnam Medical Journal, vol. 50, no. 3, pp. 82-85, 2014.

[105] E. Turkoglu, E. Celik, and G. Alagoz, "A comparison of the efficacy of autologous serum eye drops with amniotic membrane transplantation in neurotrophic keratitis," Seminars in Ophthalmology, vol. 29, no. 3, pp. 119-126, 2014.

[106] A. Erices, P. Conget, and J. J. Minguell, "Mesenchymal progenitor cells in human umbilical cord blood," British Journal of Haematology, vol. 109, no. 1, pp. 235-242, 2000.

[107] P.-F. Choong, P.-L. Mok, S.-K. Cheong, and K.-Y. Then, "Mesenchymal stromal cell-like characteristics of corneal keratocytes," Cytotherapy, vol. 9, no. 3, pp. 252-258, 2007.

[108] M. W. Varner, N. E. Marshall, D. J. Rouse et al., "The association of cord serum cytokines with neurodevelopmental outcomes," American Journal of Perinatology, vol. 30, no. 2, pp. 115-122, 2015.
[109] K.-C. Yoon, H. Heo, S.-K. Im, I.-C. You, Y.-H. Kim, and Y.G. Park, "Comparison of autologous serum and umbilical cord serum eye drops for dry eye syndrome," American Journal of Ophthalmology, vol. 144, no. 1, pp. 86.e2-92.e2, 2007.

[110] P. Versura, M. Buzzi, G. Giannaccare et al., "Cord blood serumbased eye drops: the impact of donor haematological and obstetric factors on the variability of epidermal growth factor levels," Blood Transfusion, vol. 12, supplement 1, pp. s44-s50, 2014.

[111] P. Versura, V. Profazio, M. Buzzi et al., "Efficacy of standardized and quality-controlled cord blood serum eye drop therapy in the healing of severe corneal epithelial damage in dry eye," Cornea, vol. 32, no. 4, pp. 412-418, 2013.

[112] N. Sharma, M. Goel, T. Velpandian, J. S. Titiyal, R. Tandon, and R. B. Vajpayee, "Evaluation of umbilical cord serum therapy in acute ocular chemical burns," Investigative Ophthalmology \& Visual Science, vol. 52, no. 2, pp. 1087-1092, 2011.

[113] S. Sriram, D. J. Gibson, P. Robinson et al., "Assessment of antiscarring therapies in ex vivo organ cultured rabbit corneas," Experimental Eye Research, vol. 125, pp. 173-182, 2014.

[114] K.-C. Yoon, H.-J. Oh, J.-W. Park, and J. Choi, "Application of umbilical cord serum eyedrops after laser epithelial keratomileusis," Acta Ophthalmologica, vol. 91, no. 1, pp. e22-e28, 2013.

[115] M. A. Arain, A. J. Dar, and L. Adeeb, "Autologous serum eye drops for the treatment of persistent corneal epithelial defects," Journal of the College of Physicians and Surgeons Pakistan, vol. 23, no. 10, pp. 737-739, 2013. 




The Scientific World Journal
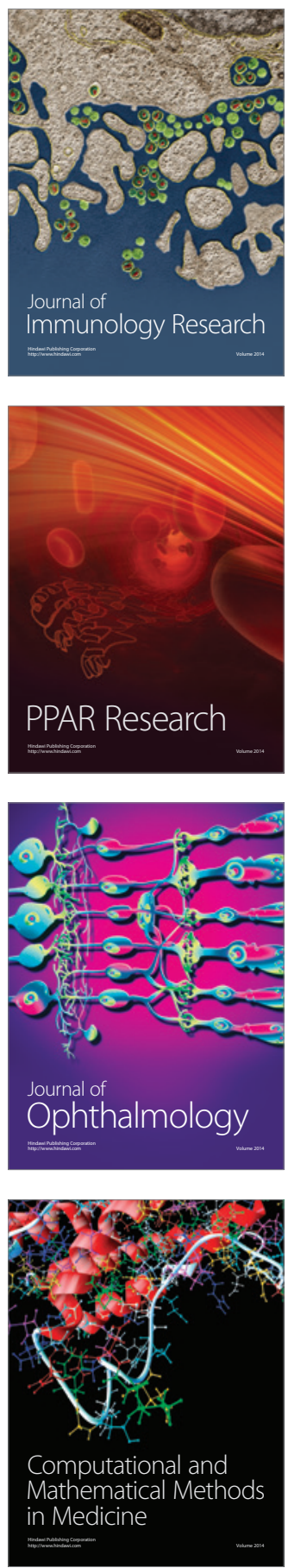



Gastroenterology

Research and Practice
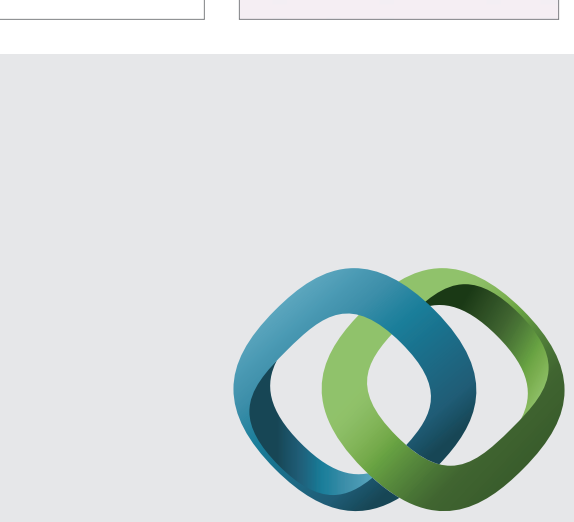

\section{Hindawi}

Submit your manuscripts at

http://www.hindawi.com
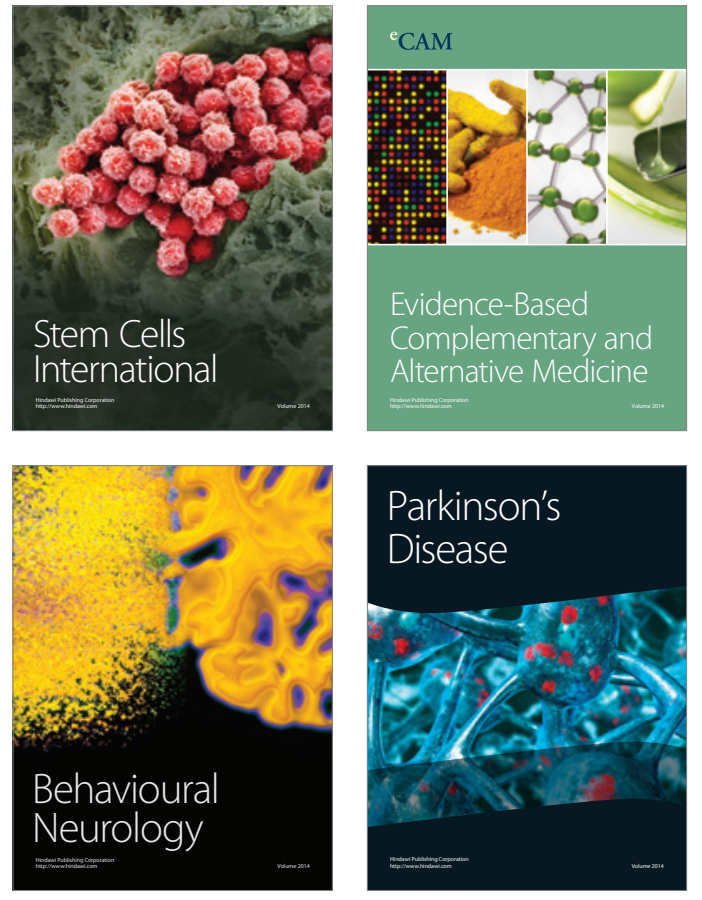
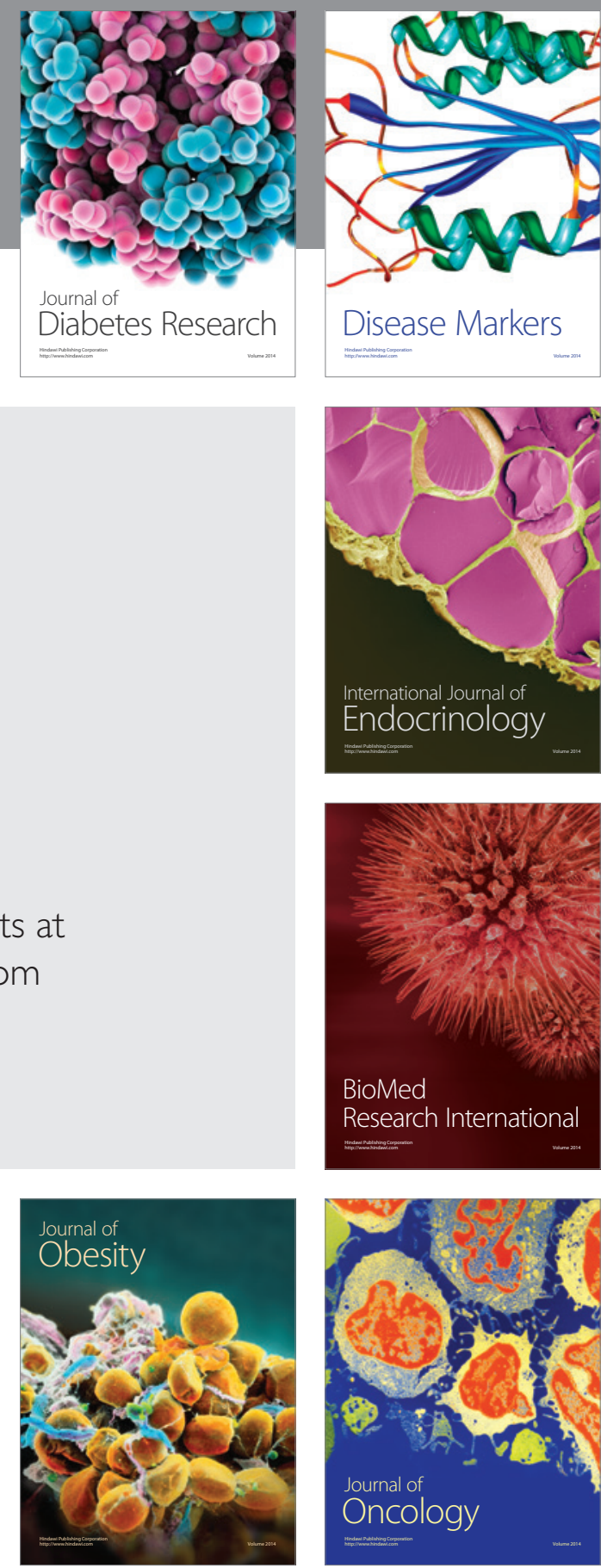

Disease Markers
